\title{
Atmospheric Response to SST Anomalies. Part II: Background-State Dependence, Teleconnections, and Local Effects in Summer
}

\author{
STEPHEN I. THOMSON AND GEOFFREY K. VALLIS \\ University of Exeter, Exeter, United Kingdom
}

(Manuscript received 6 October 2017, in final form 23 July 2018)

\begin{abstract}
In this paper and its companion, Part I, we explore the response of the atmosphere to sea surface temperature anomalies in different geographical locations and seasons. In Part I, we focused on Northern Hemisphere winter (DJF), whereas in this paper, Part II, we focus on summer (JJA) and interseasonal comparisons. We use two different configurations of the same idealized atmospheric model, constructed using two different configurations of continents and topography. These configurations give rise to slightly different background wind fields and variability within the same season and therefore give a measure of how robust a response is to small changes in the background state. We characterize the types of responses that are found to SST anomalies in the midlatitudes and tropics in JJA and compare these with the two corresponding responses in DJF. We find that the responses to midlatitude SST anomalies in JJA are generally on a much smaller spatial scale than those in DJF. Responses in the tropical Pacific are much less dependent on season, although teleconnections between the tropical Pacific and the North Atlantic are not found in JJA as robustly as they are in DJF. Given insight from our model results, however, we do find some summer periods in reanalysis data where there is a strong association between the tropical Pacific and the summer North Atlantic Oscillation. We discuss the reasons for these effects and the implications for Northern Hemisphere seasonal prediction in summer.
\end{abstract}

\section{Introduction}

The response of the atmosphere to sea surface temperature (SST) anomalies is a problem that has been studied extensively using a wide range of techniques, ranging from analytical studies in simplified equation sets (e.g., Matsuno 1966; Gill 1980) to fully coupled chemistry-climate models (e.g., Hurwitz et al. 2012). A significant difficulty with such studies is that the response of the atmosphere, particularly in midlatitudes, is thought to depend strongly on the background wind climatology and variability. In particular, Peng and Robinson (2001) showed that the response of the atmosphere to midlatitude SST anomalies depends strongly on when during winter the anomaly was present, with their results showing the response in January having a very different character to the response in February. The focus of the present work is to investigate if this same kind of dependence is present in Northern Hemisphere summer and more generally to

Corresponding author: Stephen I. Thomson, stephen.i.thomson@ gmail.com understand the circumstances under which SST anomalies can have a robust effect on the atmosphere. A companion paper (Thomson and Vallis 2018, hereafter Part I) looked at similar issues in winter.

Much previous work on the atmospheric response to SST anomalies has focused on the winter months. Notable exceptions to this include studies of the impact of Atlantic multidecadal variability (AMV) on the summertime circulation over North America, Europe, and Sahel Africa (Sutton and Hodson 2005, 2007; Hodson et al. 2010). The recent work of Ghosh et al. (2017) also focuses on the impact of AMV variability but specifically on its impact on the North Atlantic European region in summer. They find a region of ocean-to-atmosphere heat flux resulting in a downstream low pressure center. Such a response is typical of the cold-air-advection response to surface heating described in Hoskins and Karoly (1981). A similar wave train response in summer was found on seasonal time scales in the combined reanalysis and model study of Saeed et al. (2014).

Despite the previous focus on the winter months, understanding the impact of SST anomalies on the 
atmosphere in summer is nevertheless of great importance, with the ocean thought to play a role in determining both climatological conditions (Dong et al. 2013) and extreme events, such as heat waves (McKinnon et al. 2016). Atmospheric predictability coming from SSTs is better established in winter (e.g., Scaife et al. 2017, and references therein), but the reasons for this are unclear. Some recent studies using reanalysis data have shown that there may be some skill in summer in predicting the summer east Atlantic (SEA) pattern (Ossó et al. 2017; Wulff et al. 2017), as well as the influence of the tropical and subpolar Atlantic on summertime North Atlantic circulation (Gastineau and Frankignoul 2015). However, difficulties in making these links operational remain, likely because of the lack of robust model responses to summertime midlatitude SST anomalies (Hodson et al. 2010).

In this paper, we investigate the dependence of atmospheric responses to SST anomalies on background climatology in Northern Hemisphere summer [June, July, and August (JJA)] with the goal of gaining a better understanding of seasonal differences. As in Part I, this is done by using an idealized general circulation model with two different configurations of continents and topography. The differences in responses to SST anomalies in these two configurations are then interpreted in the light of their different climatologies.

The outline of this paper is as follows. Section 2 describes the model and its two different configurations and compares the model's climatologies and variability with reanalysis. Section 3 outlines our design for SST anomaly experiments, section 4 discusses the response to tropical anomalies, section 5 discusses the response to midlatitude anomalies, section $6 \mathrm{com}-$ pares the responses to tropical and midlatitude SST anomalies, section 7 investigates teleconnections between the tropical Pacific and the North Atlantic during JJA, section 8 discusses and draws conclusions about the summer results, and section 9 discusses the combined conclusions and results from Part I and Part II.

\section{Model setup and comparison of model climatologies and reanalysis}

As in Part I, we construct our models using Isca (Vallis et al. 2018). The model constructed here is of intermediate complexity, with realistic radiative transfer but with simple convection, boundary layer, and surface schemes. The mixed layer ocean uses prescribed heat transport ( $Q$ fluxes) to keep the basic-state SSTs close to an annually repeating but seasonally varying SST climatology from AMIP (Taylor et al. 2000).
Further details can be found in the appendix of Part I. Isca is run with two different configurations of land and topography in order to generate slightly different climatological states. The first is a "simple" configuration of continents and simplified topography, which are shown in Fig. 1a. By contrast, the "complex" configuration uses realistic continent shapes and topography taken from the ERA-Interim invariants (Dee et al. 2011). This continental configuration is shown for comparison in Fig. 1b. In addition to the differentiating features described above, the complex configuration has a very simple representation of sea ice and land ice, where the simple configuration does not. Further information is provided in Part I.

In order for our comparison of atmospheric responses to SST anomalies in these two configurations to make sense, it is required that the climatologies of the two configurations are similar to one another but not identical. If their climatologies were either very different or identical, then the comparison would be meaningless. These climatological states should also be similar to the real world in order that conclusions are applicable to real-world problems. Part I made such a comparison in DJF. Here, we make the comparison in JJA, with Figs. 1d and 1e showing the 20-yr time-mean zonal wind at $850 \mathrm{hPa}$ in JJA in the simple and complex configurations, respectively, with Fig. If showing the same field in the JRA-55, averaged between 1958 and 2016 (Kobayashi et al. 2015). Broadly speaking, the two model configurations are similar to each other in terms of their wind structure and magnitudes. Some small differences are apparent, however, particularly in the strength of the jet in the west Pacific and the position of the maximum winds in the jet over the North Atlantic. A comparison between the two configurations and JRA-55 shows that, again broadly speaking, our model wind distributions and magnitudes look quite like reanalysis. Some notable differences are in the latitude of the jet stream over the North Pacific and the southwest-northeast tilt of the jet stream over the North Atlantic, with the models' jet streams being too zonal. A similar comparison can be made between the two model configurations and JRA-55 at other vertical levels, and similar conclusions apply. For example, Figs. $1 \mathrm{~g}-\mathrm{i}$ are equivalent plots to Figs. $1 \mathrm{~d}-\mathrm{f}$ at $250 \mathrm{hPa}$.

The modes of variability found in the two configurations and in JRA-55 are also similar but not identical. This is important because the projection of the atmospheric response onto internal modes of variability is often seen in DJF (e.g., Part I or Peng and Robinson 2001). Figure 2 shows EOF1 of the zonal wind at $250 \mathrm{hPa}$ in JJA, calculated separately over two latitude-longitude regions using 


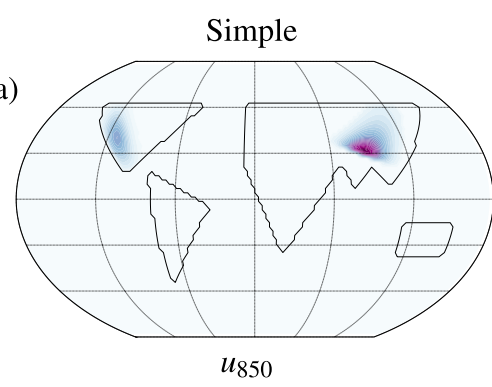

(d)

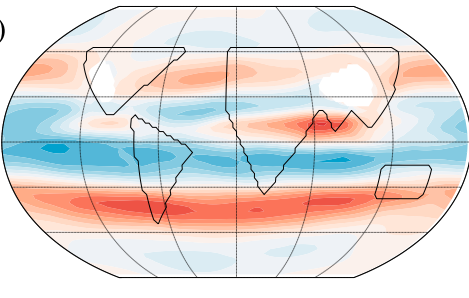

$u_{250}$

(g)

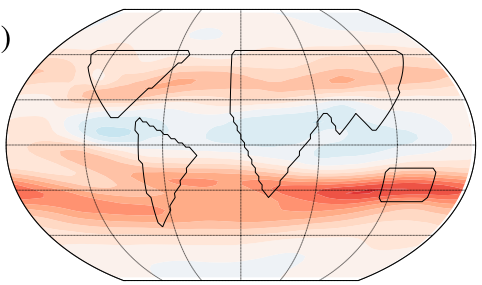

Complex

(b)

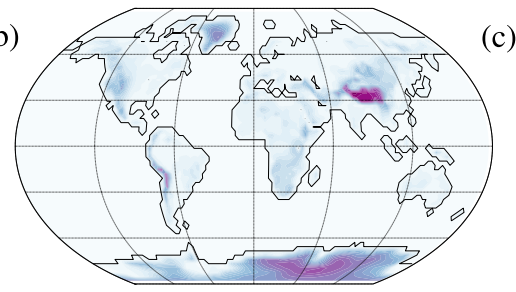

$u_{850}$

(e)

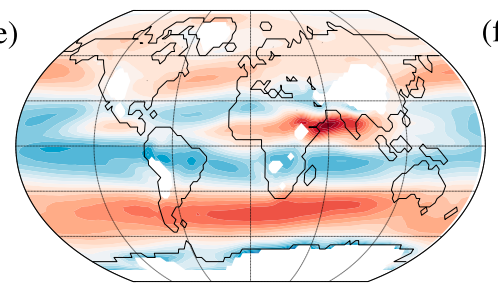

$u_{250}$

(h)

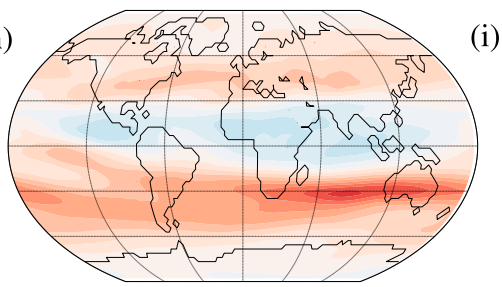

(f)

(i)
JRA-55
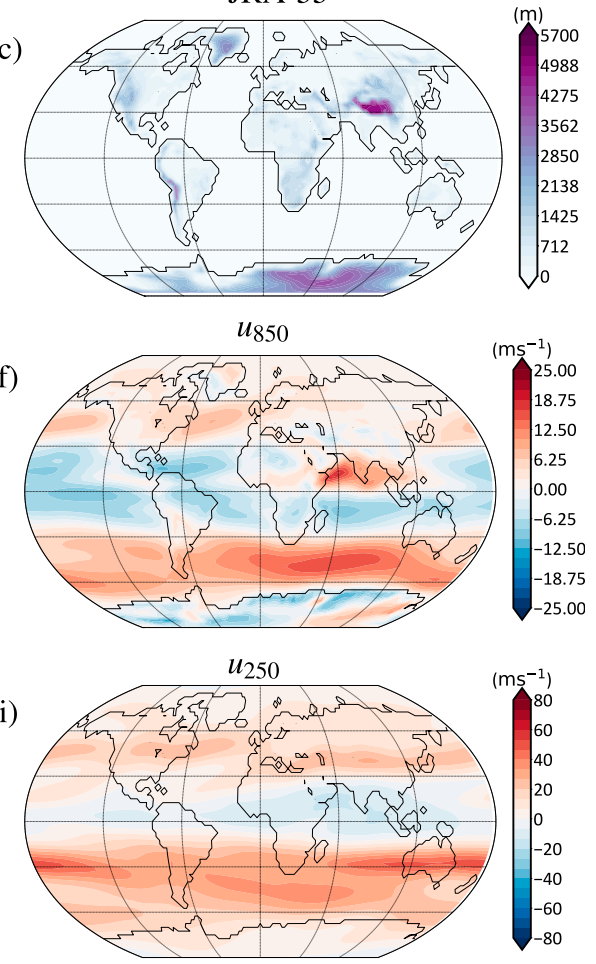

FIG. 1. A comparison of (a)-(c) the topographic height and the zonal wind at (d)-(f) 850 and (g)-(i) $250 \mathrm{hPa}$ in JJA in (left) the simple configuration, (center) the complex configuration, and (right) JRA-55.

monthly mean data. These regions are the North Atlantic ${ }^{1}$ $\left(20^{\circ}-90^{\circ} \mathrm{N}, 80^{\circ} \mathrm{W}-40^{\circ} \mathrm{E}\right)$ and the North Pacific $\left(20^{\circ}-90^{\circ} \mathrm{N}\right.$, $\left.120^{\circ}-240^{\circ} \mathrm{E}\right)$. The modes over the North Pacific are very similar in structure and magnitude in all three cases. Over the North Atlantic, the complex configuration's mode looks relatively similar to the mode in JRA-55, albeit with the positive jet feature being too far south in the complex configuration. The simple configuration's mode is a little different; however, all of these modes correspond to a latitudinal shift of the jet stream, so the modes are indeed describing the same physical mode of the system. Given all this, we regard our two configurations as being both similar enough and different enough to each other and to JRA-55 to make a comparison meaningful.

\section{Response to the Gulf Stream}

In order for us to reason that our SST anomaly-induced responses are somewhat realistic, it seems natural to first verify that the SST-induced atmospheric responses in the

\footnotetext{
${ }^{1}$ The EOFs calculated over the Atlantic correspond to the summer NAO (Folland et al. 2009) mode of variability, although the sign of the EOF is opposite to the definition found in Folland et al. (2009), meaning that a positive projection onto our EOF corresponds to a state of negative summer NAO.
}

basic state are realistic. To this end, we have checked the response of the atmosphere to the Gulf Stream.

In observations, the atmosphere responds to the Gulf Stream by way of a convergence on the warm side of the SST front and precipitation that is tied closely to the Gulf Stream axis (Minobe et al. 2008, 2010). This pattern is observed in JJA as well as in DJF, although the overall amplitude is weaker in JJA. In both our simple and complex configurations in JJA, we similarly find convergence over the warm side of the Gulf Stream and precipitation along its axis, with the response weaker than in DJF, as observed. We do not find the same association between the Laplacian of SLP and atmospheric convergence as was found in our model in DJF, suggesting the DJF surface convergence mechanism may be too weak in our JJA basic state, possibly because of a lack of horizontal resolution. Nevertheless, other aspects of a realistic response to the Gulf Stream are reproduced, particularly the vertical structure of the atmospheric upwelling over the Gulf Stream region, whose magnitudes compare well with JRA-55 (not shown).

\section{Experiment design}

To study the atmospheric responses to SST anomalies, we follow the same procedure as in Part I, to which the 

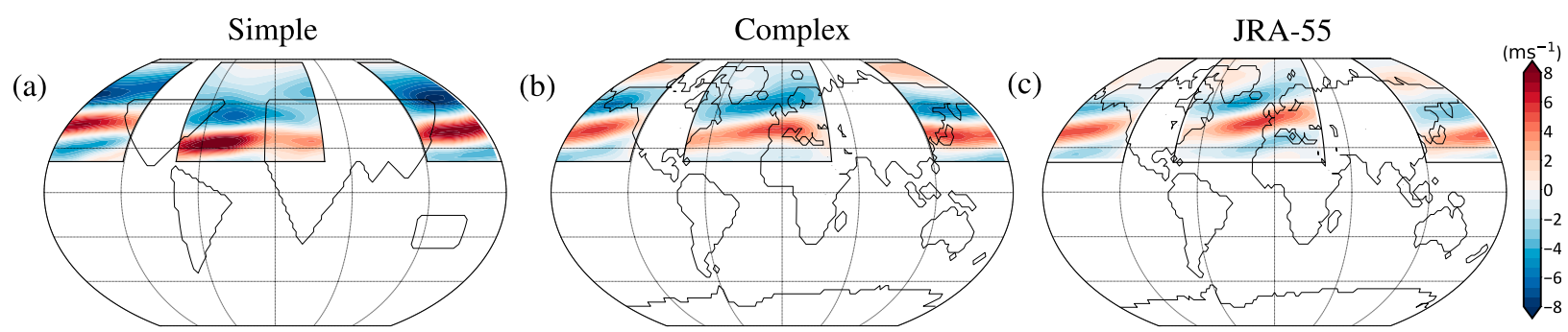

FIG. 2. (a) The first EOFs of the 250-hPa zonal wind in JJA in the simple configuration, calculated separately in the Atlantic and Pacific basins. Dark lines mark the domain over which the EOF was calculated. (b),(c) As in (a), but for the complex configuration and JRA-55, respectively. The EOFs are calculated from data north of $20^{\circ} \mathrm{N}$.

reader is referred for details. We do, however, remind the reader of our robustness definition for clarity. For a response to be deemed "robust," we require that it meets two criteria:

1) The response in a particular quantity must be similar across the two configurations.

2) The responses within the two configurations must both be statistically significant, as judged by the $t$ test with a $95 \%$ confidence limit.

The responses produced by a particular SST anomaly in our two configurations can therefore have both robust and nonrobust components; that is, the local responses in two cases might be the same across the configurations, but the remote responses may be different. We would then classify the local response as robust but the remote response as not being robust. In what follows, we will focus our analysis on the zonal-wind responses at $250 \mathrm{hPa}$. We have chosen this level because of its usefulness for diagnosing the free-atmosphere responses, as these are more likely to be useful for teleconnections and predictability than, for example, shallow, boundary layer responses.

We use the same 31 different locations for our SST anomalies as in Part I, and these are shown in Fig. 3a. Each of these locations is run separately for each configuration, giving a total of 62 experiments.

\section{Responses to tropical anomalies}

To summarize the responses found in each of the 62 experiments, we have focused on the response of the zonal wind at $250 \mathrm{hPa}$ and have categorized the response to each anomaly into as many of the following seven categories as are relevant:

- None of the below: The response displays none of the characteristics of the other six categories.

- Local anticyclonic circulation: A statistically significant anticyclone at $250 \mathrm{hPa}$, indicative of the local linear-like response described in, for example, Hoskins and Karoly (1981).

- Matsuno-Gill like: A statistically significant response displaying the broad characteristics of the simple linear responses to tropical heating described in Matsuno (1966) and Gill (1980), specifically, lowlevel convergence and upper-level divergence.

- NAO like: A statistically significant response over the North Atlantic sector looks like either a positive or negative summer NAO-like state. For some cases, this will constitute a local response, and for others (e.g., NAO-like responses to tropical Pacific SST anomalies), it will constitute a remote teleconnection response.

- Eastward winds over equatorial Atlantic: Broad region of eastward winds over the equatorial Atlantic.

- Central African anomalies: Broad category incorporating small circulation anomalies over central and northern Africa.

- Cyclone over central Atlantic: Small cyclonic circulation over the central northern Atlantic.

The categories above were chosen to represent the seven most common types of responses across all the summer experiments. To represent these categories graphically, we have assigned each category a color and have color coded a circle in the SST anomaly's location by the kind of response they produce. Figure $3 \mathrm{~b}$ shows the responses produced by SST anomalies in the complex configuration. Figure $3 \mathrm{c}$ shows the responses produced by SST anomalies in the simple configuration. Figure $3 \mathrm{~d}$ shows the robust responses, being the responses to each SST anomaly that are common across both the configurations.

The broad summary of this section is seen in Fig. 3d, namely, that robust summer responses (at least locally) are found in all but one of the tropical SST anomalies. This is in stark contrast to the responses to the midlatitude anomalies, where around half of the anomalies did not produce a robust response. This qualitative result is the same in winter, as discussed in Part I. 

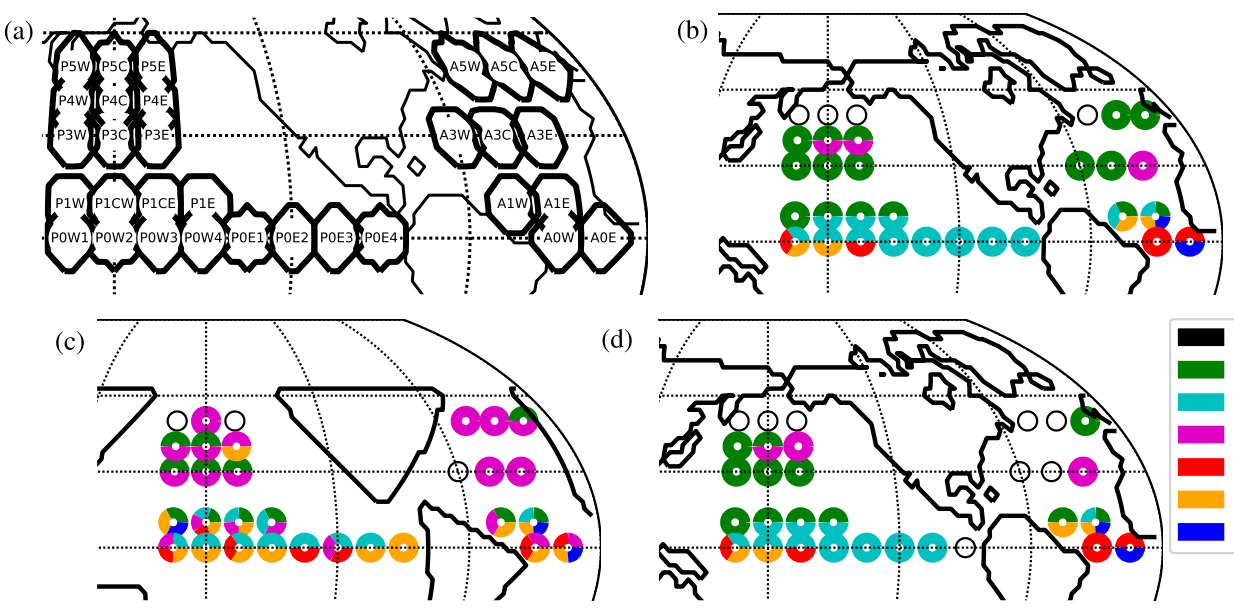

(d)

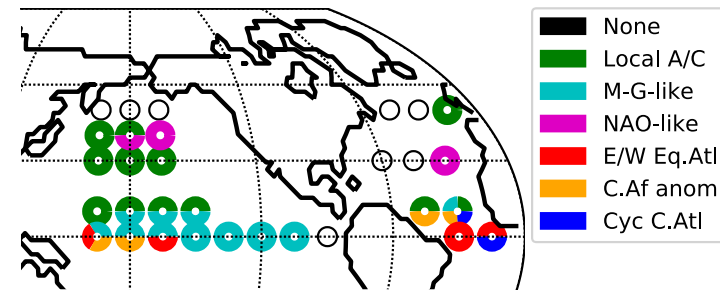

FIG. 3. (a) The name given to each location. Also shown is a summary of the various responses produced in each of the SST anomaly experiments. The variable used to define these responses is the JJA-mean zonal wind at $250 \mathrm{hPa}$. (b) The responses in each of the complex configuration experiments, with the colors denoting the type of response. (c) As in (b), but for the simple configuration. (d) The responses that are common across (a) and (b), which are the so-called robust responses.

\section{a. Tropical response to tropical Pacific SST anomalies}

We begin by considering the response of the tropical atmosphere to tropical SST anomalies, which we refer to as the "local" responses to the tropical anomalies.

Of the 12 locations considered in the tropical Pacific, 11 produce robust local responses, being the same local responses in both configurations. This local response is generally classified as being Matsuno-Gill-like, with the standard differences being displayed between anomalies on and off the equator [for further details, see chapter 8 of Vallis (2017)].

Given the well-known differences between MatsunoGill-like responses on and off the equator, the main contrast between the tropical Pacific responses comes in their changes with longitude. Cases at $10^{\circ} \mathrm{N}$, for example, show a relatively weak response to the two westernmost cases but a significantly stronger and zonally broader response to the two easternmost cases, and this is seen in both configurations. These stronger and broader responses significantly weaken the JJA Walker circulation, consistent with the weakening of the eastwest Pacific SST gradient by warming in the east. It is, however, to be noted that the JJA Walker circulation is much stronger in both model configurations than in JRA-55 (not shown), meaning this aspect may not be realistic.

The idea of the easternmost cases producing the strongest responses goes against the work of Bony et al. (1997), who suggest that tropical SST anomalies produce a stronger response in the west Pacific in areas of upwelling and a weaker response in the east Pacific in areas of downwelling. However, Bony et al. (1997) discusses the strength of the associated upwelling rather than zonal wind at $250 \mathrm{hPa}$. Considering then the anomalous upwelling, at $10^{\circ} \mathrm{N}$, there is a hint of this kind of east-west contrast in our two configurations, with the easternmost case at $10^{\circ} \mathrm{N}$ having weaker upwelling than cases to its west. Why the zonal-wind responses at $250 \mathrm{hPa}$ have a larger response in the two easternmost cases is therefore not explained, although the large strength of the model's Walker circulation in JJA when compared with that in JRA-55 may be related. We do, however, see a longitudinal contrast in upwelling in our equatorial cases, with the westernmost cases having stronger anomalous upwelling than eastern cases, consistent with Bony et al. (1997).

In general, the local responses to these Pacific SST anomalies are all remarkably similar to those in DJF, implying a robustness to the seasonally changing background wind field.

\section{b. Extratropical responses to tropical Pacific SST anomalies}

There are many fewer cases of significant extratropical responses compared with DJF. In fact, over the North Pacific, there are no cases with significant responses to tropical Pacific SST anomalies in JJA. The DJF responses in the North Pacific were mostly changes in the Aleutian low, which is not present in JJA, so this lack of response in JJA seems reasonable.

There is also a lack of response to tropical Pacific SST anomalies in the North Atlantic. To see this, we 

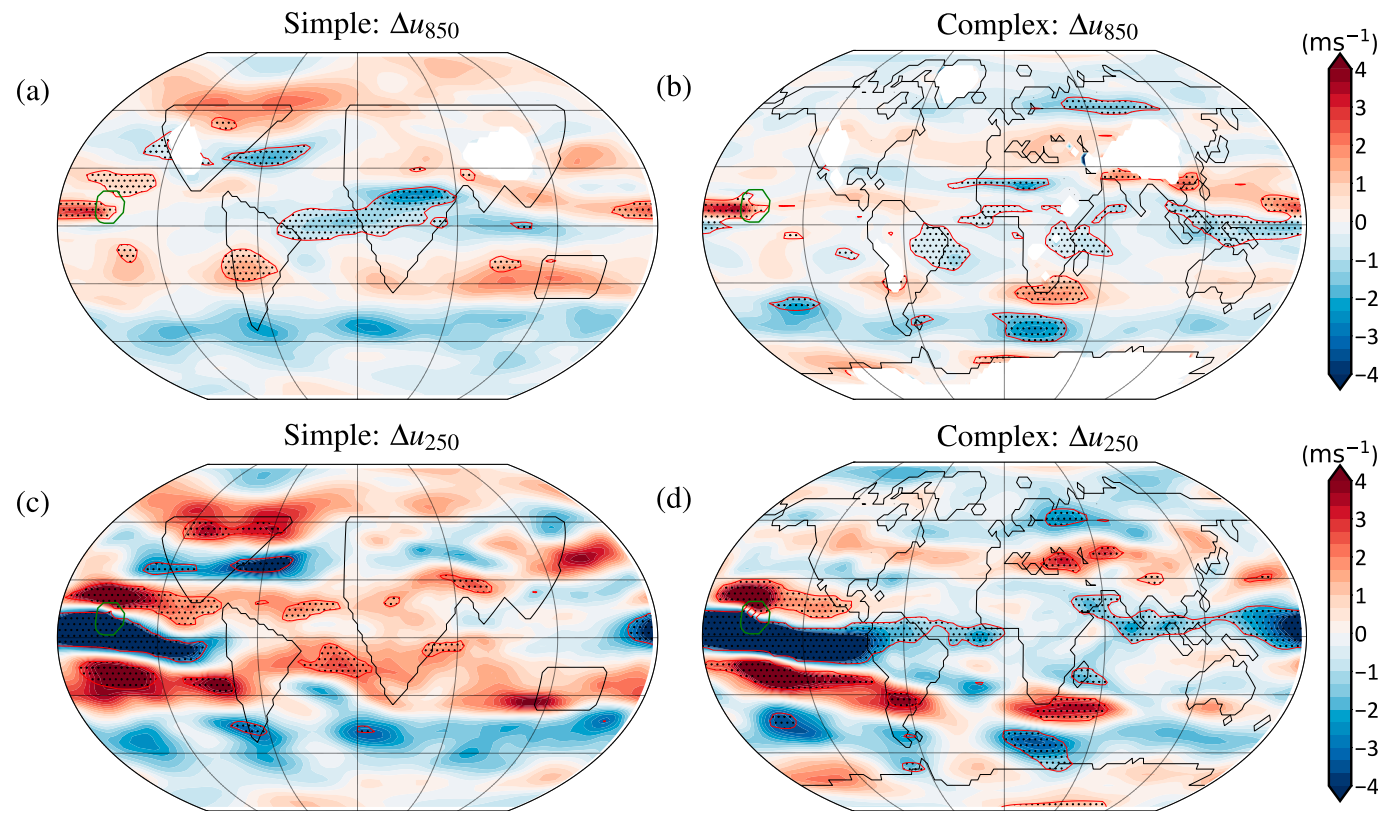

FIG. 4. Time-mean responses to $Q$-flux anomaly in case P1E in JJA for the (left) simple and (right) complex configurations at (a),(b) 850 and (c),(d) $250 \mathrm{hPa}$.

calculate correlation coefficients between the zonalwind response at $250 \mathrm{hPa}$ and EOF1 of zonal wind at $250 \mathrm{hPa}$ over the North Atlantic. This is done separately for the two configurations. We then plot the correlation coefficient in the simple configuration against the correlation coefficient in the complex configuration for each case. This plot is shown later (see Fig. 5a, below), with the coefficients from the simple configuration on the $x$ axis and the coefficients from the complex configuration on the $y$ axis. Any cases that have both high correlation coefficients and similar coefficients in the two configurations are deemed to have a robust projection of the response onto EOF1. The robustness of the overall response, however, is determined purely by the two criteria in section 3 , with only the robustness of the EOF projection measured by these correlation coefficients. The lack of significant remote responses can be seen in the lack of high correlation coefficients between the responses and the summer EOF1s in the North Atlantic (see Fig. 5a, below).

The lack of robust projections onto the summer NAO over the North Atlantic is mainly due to the lack of summer NAO responses in the complex configuration, with the simple configuration showing many examples of a summer-NAO-like response. These are cases P1CW, P1CE, P1E (seen in Fig. 4), P0W1, and P0E2 (refer to Part I for naming conventions). We suggest two possible explanations for this contrast between configurations. The first is the prevalence of the summer NAO in the simple configuration's basic state (i.e., that the summer NAO's EOF representation explains much more of the variance in the simple configuration than in the complex configuration and JRA-55). It seems likely that this prevalence would make the summer NAO pattern more likely to appear as a forced response in the simple configuration, as is found. The second possible explanation is that linear Rossby waves are able to propagate more easily between the tropics and midlatitudes in the simple configuration than in the complex configuration. These two explanations are discussed in sections $5 \mathrm{a}$ and 7 , respectively.

\section{c. Responses to tropical Atlantic SST anomalies}

A noteworthy feature of the responses to tropical Atlantic SST anomalies is that only one of the four relevant SST anomalies show a robust Matsuno-Gill-like response. Of the four relevant SST anomalies, the two equatorial anomalies do not produce Matsuno-Gill-like responses in either configuration in JJA. The responses, instead, are robust eastward winds over a broad latitudinal region over the equatorial Atlantic. This lack of Matsuno-Gill-like responses to equatorial Atlantic anomalies is seasonal, however, with Matsuno-Gill-like responses present in these cases in every season apart from JJA.

Regarding the two anomalies off the equator, the presence of a Matsuno-Gill-like response in case A1W in the complex configuration but not in the simple 
(a)

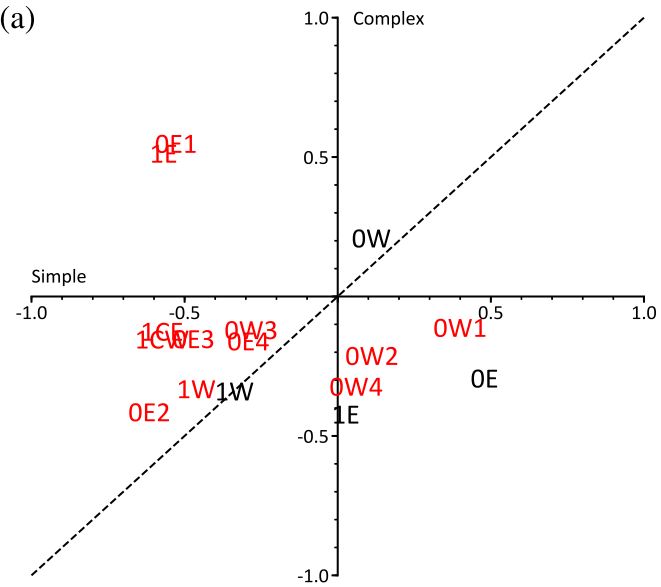

(b)

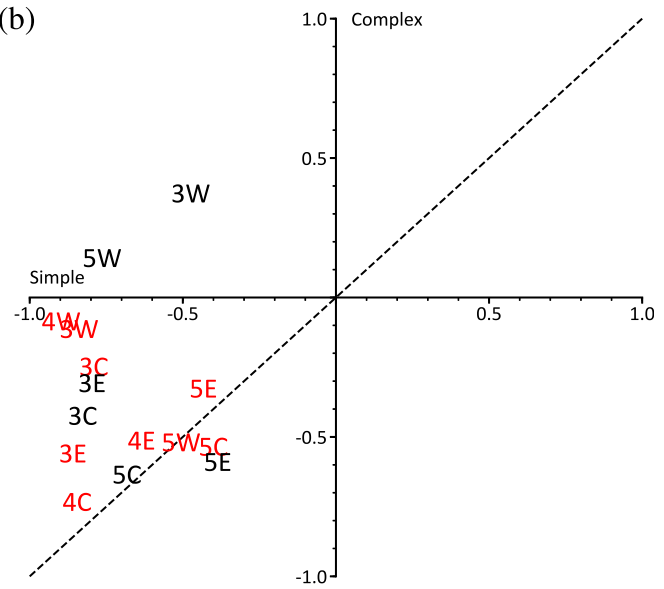

FIG. 5. (a) Comparison of correlation coefficients in the simple configuration ( $x$ axis), with correlation coefficients in the complex configuration ( $y$ axis). The correlation coefficients are calculated between the zonal-wind response in JJA at $250 \mathrm{hPa}$ in cases with tropical SST anomalies and the EOF of zonal wind in JJA over the Atlantic basin $\left(80^{\circ} \mathrm{W}-40^{\circ} \mathrm{E}\right)$. The dashed line is $y=x$. The colors denote the basin in which the anomaly is placed, with red being in the Pacific and black being in the Atlantic. The code used at each point corresponds with Fig. 3 without the letter denoting the basin. (b) As in (a), but for the midlatitude SST anomalies. It is noted that our classification of a robust response is based purely on the two criteria in section 3 and that these plots only serve as a guide as to how robust the projection onto the leading EOF is.

configuration suggests some sensitivity to the background wind field. The responses in the two cases are somewhat similar, but the negative anomaly that extends to the west at $250 \mathrm{hPa}$ in Matsuno-Gill-like cases instead extends to the south in the simple configuration. We hypothesize that the different shape of the South American continent in the simple configuration is somehow able to disrupt the normal Matsuno-Gilllike circulation, although further investigation into this idea is required. This idea is supported, however, by the fact that the adjacent case A1E, which is farther off the South American coast, does produce a robust Matsuno-Gill-like response.

In terms of remote responses, there are two robust cases in the tropical Atlantic that produce anomalies over central Africa and many cases in the tropical Pacific in the simple configuration that also produce anomalies over central Africa. The influence of tropical Atlantic SSTs on North Africa is suggestive of previously discussed effects of the AMV on North Africa, as in Sutton and Hodson (2005). In addition, some of our cases in the tropical Atlantic, namely, cases $\mathrm{A} 1 \mathrm{~W}$ and $\mathrm{A} 1 \mathrm{E}$, produce robust zonal-wind responses over the tropical Pacific. This is also consistent with Sutton and Hodson (2005), who show the impact of tropical Atlantic SSTs on the tropical Pacific in their Fig. 3a.

In terms of other remote responses, none of the tropical Atlantic anomalies stand out as having high correlations with the Atlantic EOF1 in Fig. 5a. However, as discussed previously, the simple configuration does produce three cases that look somewhat NAO-like, where the complex configuration does not. Discussion of the prevalence of the summer NAO in the simple configuration is again deferred to section 5 a.

A significant non-summer-NAO-like remote response is found in the two easternmost cases, which produce a small cyclonic circulation over the North Atlantic, as can be seen for case A0E in Figs. 6a and 6b. This suggests that a robust connection between the tropics and the midlatitudes may well be possible in JJA in the Atlantic, although this link may not be with the summer NAO, as suggested in Ossó et al. (2017) and Wulff et al. (2017).

\section{Responses to midlatitude anomalies}

The responses to midlatitude SST anomalies show the most contrast between configurations. Of the 15 midlatitude locations, in the complex configuration, 10 of them produce local anticyclonic circulations and 3 produce summer NAO-like responses, whereas in the simple configuration, 6 of them produce local anticyclonic circulations and 12 produce summer NAO-like responses. The prevalence of the local anticyclonic circulation, which is robust in 6 of the 15 cases, is perhaps unsurprising, given that it is part of the expected linear response to midlatitude surface heating. It is noted, however, that while most of these cases have corresponding surface cyclonic circulations, as predicted by linear theory, several do not, suggesting that the lower 


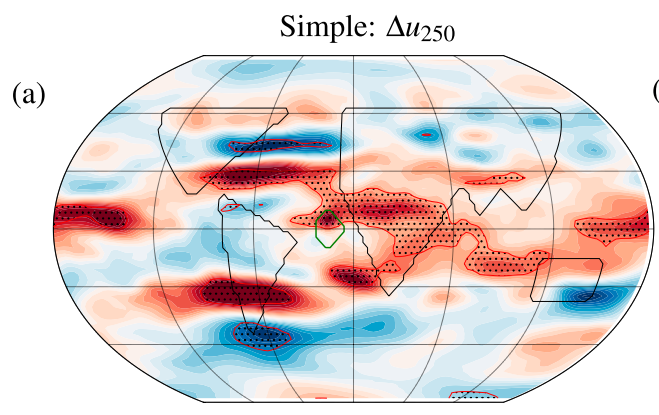

(b)

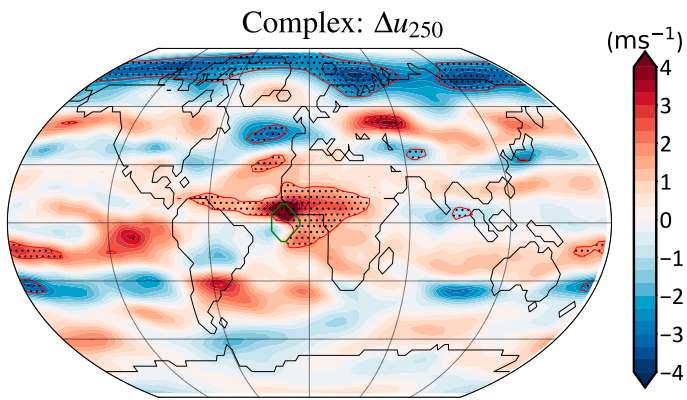

FIG. 6. Time-mean responses of the zonal wind at $250 \mathrm{hPa}$ to $Q$-flux anomaly in case A0E in JJA for the (a) simple and (b) complex configurations.

portion of the response is hidden by near-surface variability. As regards summer NAO-like responses, Pacific cases $\mathrm{P} 4 \mathrm{C}$ and $\mathrm{P} 4 \mathrm{E}$ produce robust remote responses over the North Atlantic, in contrast to the adjacent case $\mathrm{P} 4 \mathrm{~W}$ and those at $30^{\circ} \mathrm{N}$. These responses correlate strongly with EOF1 over the Atlantic in both configurations, having correlation coefficients that are close to the $y=x$ line in Fig. 5b. The responses in the two configurations, although similar to their respective EOF1s, are somewhat different to each other in spatial structure (not shown), although this is simply a reflection of the difference in EOF structure between the two cases. This underlines the importance of accurately simulating modes of internal variability for getting a robust response to SST anomalies.

Other cases that have reasonably high correlation coefficients in Fig. $5 \mathrm{~b}$ are the easternmost cases in the Atlantic at $50^{\circ} \mathrm{N}$. The response in cases $\mathrm{A} 5 \mathrm{C}$ and $\mathrm{A} 5 \mathrm{E}$ somewhat resembles those in case $\mathrm{P} 4 \mathrm{C}$, particularly in the simple configuration, which has a strong EOF-like barotropic response. The complex configuration's response is much weaker than in the simple configuration and is baroclinic, being present at $250 \mathrm{hPa}$ but not at $850 \mathrm{hPa}$, suggesting that any surface response is hidden by the high background variability. Both these cases produce an anticyclonic circulation over the United Kingdom in the complex configuration that is similar to that seen in cases P4C and P4E. That a surface response is seen in cases $\mathrm{P} 4 \mathrm{C}$ and $\mathrm{P} 4 \mathrm{E}$ but not in cases $\mathrm{A} 5 \mathrm{C}$ and A5E perhaps suggest that cases $\mathrm{P} 4 \mathrm{C}$ and $\mathrm{P} 4 \mathrm{E}$ produce a true projection onto the model's internal modes but that A5C and A5E's response is more of a local baroclinictype response, consistent with cases P3W-P3E (see Fig. 7 for P3E plots).

Unlike the winter cases studies in Part I, there are no significant summer responses in the NH's stratosphere in either configuration. This is to be expected, however, given the inability of vertically propagating waves to propagate into the stratosphere in summer. This is due to the easterly winds in the lower stratosphere in JJA, unlike in DJF, as explained by the Charney-Drazin criterion (Charney and Drazin 1961).

\section{The summer NAO in the simple configuration}

One of the clear features seen in Fig. $3 \mathrm{c}$ is that many of the responses in the simple configuration in JJA project negatively onto EOF1 of the zonal wind in the Atlantic sector at $250 \mathrm{hPa}$. Despite these strong projections in the simple configuration, little projection onto the EOF is seen in many of the complex configuration cases in Fig. $3 b$.

One possible explanation for this difference is that the summer EOF1 over the Atlantic in the simple configuration explains $32.0 \%$ of the monthly variance, where the summer EOF1 over the Atlantic in the complex configuration explains only $23.6 \%$ of the monthly variance. It might be expected, therefore, that a model response would project more strongly onto an EOF if it explains more of the variance. The lower percentage in the complex configuration is the more realistic of the two, however, with the same EOF in JRA-55 explaining $23.3 \%$ of the monthly variance. ${ }^{2}$ Equally, the EOF's spatial pattern in the simple case is arguably less realistic than that in JRA-55, particularly in high latitudes. Both of these factors suggest that the almost ubiquitous projection onto the summer NAO by midlatitude SST anomalies in the simple cases may well be unrealistic. This therefore highlights the need for model biases in modes of variability to be as low as possible when considering a model's response to forcing.

\section{Comparison of tropical and midlatitude responses}

The results described above show a clear contrast between responses to tropical SST anomalies and

\footnotetext{
${ }^{2}$ Similar conclusions to these can be drawn from EOFs calculated using daily data, where the fractions of variance explained are $14.5 \%, 10.6 \%$, and $11.1 \%$ in the simple configuration, complex configuration, and JRA-55, respectively.
} 

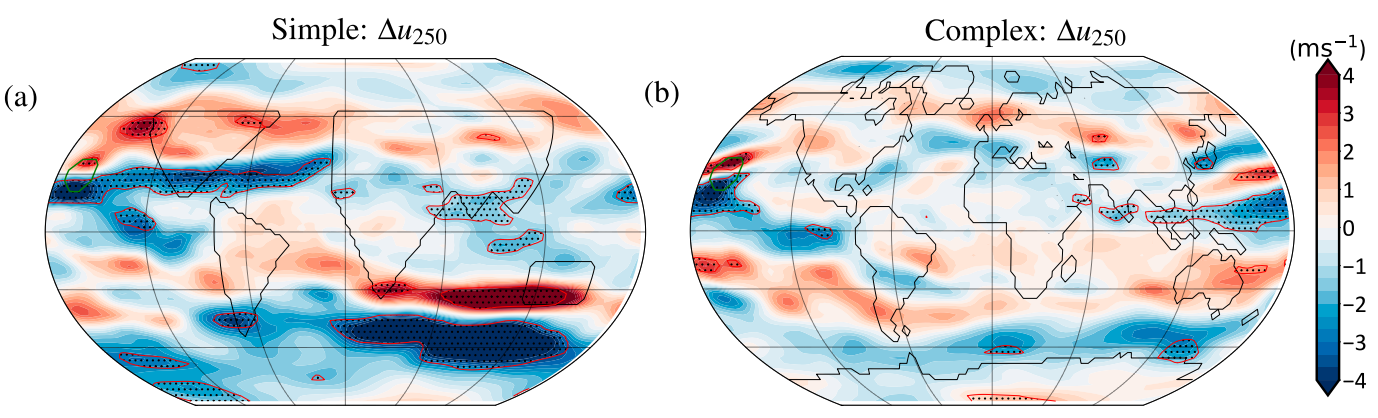

FIG. 7. As in Fig. 6, but for case P3E.

midlatitude SST anomalies in JJA. This result is consistent with a similar contrast discussed in DJF in Part I, as is well known (Hoskins and Karoly 1981). One prevalent explanation for why the atmosphere responds differently to tropical and midlatitude SST anomalies is that the response of the atmosphere to anomalous heating is predominantly vertical advection of anomalous temperature in the tropics and horizontal advection in the midlatitudes, as discussed in, for example, Hoskins and Karoly (1981) and Frankignoul (1985). In the corresponding analysis for DJF in Part I, a typical contrast between tropical and midlatitude responses to anomalous heating was shown in Figs. 8a and 8b of Part I. The same picture applies in JJA (not shown), as might be expected, except that the latitude at which the horizontal advection terms become important lies between $30^{\circ}$ and $40^{\circ} \mathrm{N}$ rather than between $10^{\circ}$ and $30^{\circ} \mathrm{N}$ in DJF. This change in character between $30^{\circ}$ and $40^{\circ} \mathrm{N}$ in JJA may well be one of the reasons why the responses discussed in section 5 at $40^{\circ} \mathrm{N}$ in JJA in the Pacific are more similar to those at $30^{\circ} \mathrm{N}$ in the Pacific in DJF than they are to those at $40^{\circ} \mathrm{N}$ in DJF.

One intriguing feature of all of the anomalous temperature profiles seen in both the simple and the complex configurations in midlatitudes in JJA (not shown) is that none of them appear to have a significant role played by cold-air advection, as judged by the lack of positive meridional advection terms near the surface. In contrast, all of the cases considered seem to have a significant role for the vertical advection terms. This is rather unlike the expected response to midlatitude warm anomalies calculated in Hoskins and Karoly (1981).

As was discussed in Part I, the prevalence of the vertical advection term is perhaps a reflection on the strength of our SST anomalies, which may well be triggering deep convection in the midlatitude cases when perhaps weaker, and arguably more realistic, SST anomalies might not. However, the importance of the vertical temperature advection term in the basic-state response to western boundary currents in both observations (Minobe et al. 2008, 2010) and high-resolution models (Smirnov et al. 2015) may mean that such a response is in fact not unreasonable. This lack of a role for cold-air advection in summer is somewhat unlike the recent work of Ghosh et al. (2017), who found cold-air advection to be very important in summertime as a response to AMV variations. This pattern was, however, found on decadal time scales and was found in response to much weaker anomalous heat fluxes than those produced in our experiments, which may make a qualitative difference to the type of response produced.

\section{Investigating summer teleconnections}

As was noted in section $4 \mathrm{~b}$, there are several cases in the simple configuration where tropical Pacific SST anomalies produced North Atlantic responses, but there were no cases of this in the complex configuration. It is well known that a mechanism to connect the tropical Pacific and the North Atlantic is propagation of largescale stationary Rossby waves (e.g., Hoskins and Karoly 1981). A well-known feature of the summertime atmosphere is that such waves cannot propagate out of the tropics and into the midlatitudes because of the predominantly westward winds throughout the depth of the troposphere in summer (e.g., Lee et al. 2009, and references therein). It is clear, however, that the JJA-mean zonal wind in the simple configuration at $250 \mathrm{hPa}$ does have a longitudinal band where there are no westward zonal winds over the central Pacific (see Fig. 1g), meaning it is possible for large-scale waves to propagate out of the tropics in the simple configuration, and we have verified this using linear Rossby wave ray tracing (not shown). It is noteworthy that the complex configuration has westward winds in this region, as does JRA55 (Figs. 1h and 1i), meaning Rossby waves cannot escape. This contrast in basic state provides an explanation for why there is a tropical Pacific-North Atlantic connection in the simple configuration but not in the complex configuration.

As suggested by this observation, it is clearly possible for there to be a connection between the tropical Pacific 
(a)

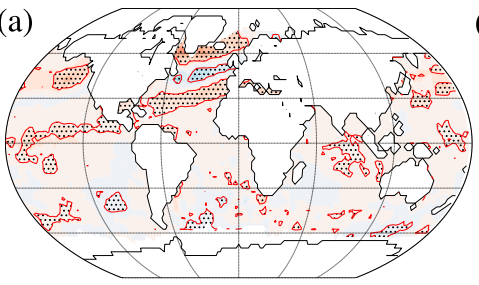

(b)

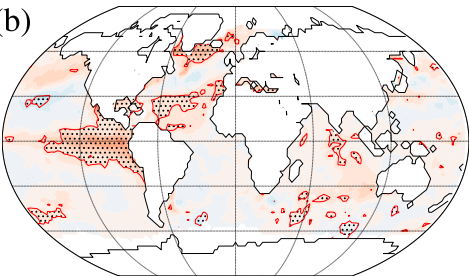

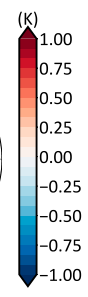

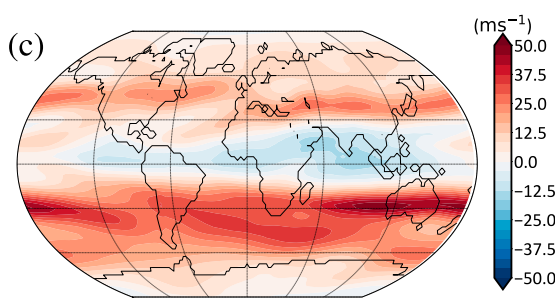

FIG. 8. (a) The linear regression coefficients of HadISST SST data regressed onto JRA-55's PC1 time series of the first EOF of the zonal wind at $250 \mathrm{hPa}$ over the Atlantic basin. (b) As in (a), but only using summer months when the time series of equatorial zonal wind at $250 \mathrm{hPa}$, averaged between $160^{\circ} \mathrm{E}$ and $170^{\circ} \mathrm{W}$, is positive. (c) A composite of the zonal wind at $250 \mathrm{hPa}$ during months when the zonal-wind index is positive.

and the North Atlantic during summer but that this connection depends on the sign of the winds in the tropics. We therefore wish to consider the possibility that natural variability in the tropical winds over the Pacific is such that there are times when eastward winds are favored, allowing Rossby wave propagation out of the tropics and into the North Atlantic. To test this idea, we looked at the zonal wind along the equator in monthly JRA-55 data at $250 \mathrm{hPa}$ and took sector averages of $60^{\circ}$ width centered on $170^{\circ} \mathrm{W}$, thus giving a single equatorial zonal-wind time series for the central Pacific. We find that the natural variability in this region is such that the winds are sometimes eastward even if they are westward for the majority of the time. Having created this index, we then calculated the linear regression between the real-world HadISST dataset (Rayner et al. 2003) and the North Atlantic EOF's PC1 from JRA-55 but calculated the regression separately for summer months when the zonal-wind time series was negative, as is normal, and for those summer months when the zonal-wind time series was positive. The regression map in the case of negative equatorial winds (not shown) looks very like the map calculated using all summer months, the latter of which is shown in Fig. 8a. However, the regression map in the case of positive equatorial winds is significantly different and is shown in Fig. $8 \mathrm{~b}$ alongside a composite of the zonalwind conditions during the summer months with a positive zonal-wind index in (Fig. 8c). It is clear from Fig. $8 \mathrm{~b}$ that there is now a much stronger association between the SSTs off the west coast of South America and the EOF in JJA, with this pattern of SSTs resembling an El Niño-like SST anomaly [e.g., Fig. 22.13(c) of Vallis (2017)]. It therefore appears that some summer months could have a strong association between tropical SSTs and the circulation over the North Atlantic, potentially leading to increased seasonal predictability for the North Atlantic during these periods. However, these periods are the exception rather than the norm. Of the 174 summer months between 1958 and 2015 in our JRA-55 and HadISST datasets, there are only 42 months $(24 \%)$ with positive equatorial winds over our predefined longitude range, with 132 months $(76 \%)$ having the standard negative equatorial winds. Using different longitude widths and central longitudes for the averaging that creates this zonal-wind time series changes these numbers somewhat, especially as the number of months where a negative zonal wind occurs decreases when the central longitude of our sector average is moved away from the central Pacific. ${ }^{3}$ However, the general pattern of the regression maps stayed the same under these changes. Further investigation of the potential causes of such a connection, and if there is a link with El Niño, is currently underway.

\section{Discussion of summer results}

In this work, we have compared the atmospheric response to small-scale SST anomalies in two different configurations of an idealized GCM. The aim of this study was to assess whether the responses in Northern Hemisphere summer depended significantly on the background climatological winds and whether SST anomalies in a particular part of the globe would be of use for increasing seasonal predictability for, for example, the summer NAO over the North Atlantic. One conclusion of this work is that the local responses to SST anomalies in the tropical Pacific are indeed robust to small changes in the background climatological winds, with the responses local to the SST anomalies proving similar across our two configurations (simple and complex). The responses to tropical Pacific SST anomalies were largely of a "Matsuno-Gill-like" pattern, with areas of strong positive zonal wind to the west of the anomaly at low

\footnotetext{
${ }^{3}$ Using a central longitude of $150^{\circ} \mathrm{W}$ and a sector width of $60^{\circ}$ gives 41 months with positive equatorial zonal winds, rather like the case centered on $170^{\circ} \mathrm{W}$. Taking a central longitude of $130^{\circ} \mathrm{W}$ gives only 10 months with positive equatorial zonal winds, a central longitude of $170^{\circ} \mathrm{E}$ gives 14 months, and a central longitude of $150^{\circ} \mathrm{E}$ gives 0 months.
} 
levels, and negative zonal-wind anomalies at upper levels, and some dependence of the responses' magnitude on longitude, as suggested in Bony et al. (1997).

In the tropical Atlantic, by contrast, non-MatsunoGill-like responses were seen in three of the four cases. The non-Matsuno-Gill-like responses to anomalies on the equator were robust across configurations, suggesting this is a robust difference between the summertime tropical Atlantic and tropical Pacific. In terms of the remote response to tropical SSTs, by and large, and with some exceptions, the tropical SST signal is unable to escape from the tropics in JJA because of the structure of the tropical winds, as is well known. There are some hints, however, that signals can sometimes propagate out of the tropical Atlantic into the North Atlantic and project onto the summer NAO, as was seen in case A0E. This is consistent with the work of Gastineau and Frankignoul (2015), who show from reanalysis data that SSTs in the subpolar and tropical Atlantic can influence summertime conditions in the North Atlantic. Investigating the mechanism for the teleconnection in this particular case will form part of our future work. Using reanalysis data, we have also shown that there are significant monthly periods during which the climatological westward winds over the equator in JJA can reverse, and during such periods, a significantly higher association is found between tropical SSTs in the eastern Pacific and the summer NAO. It is therefore possible that the tropical Pacific may indeed provide some extratropical predictability, but only during months with eastward equatorial winds.

In midlatitudes in summer, most of our SST anomalies do not produce a robust response across the two configurations. Of those that did produce robust responses, several had a very local and baroclinic character, with a small-scale cyclonic circulation at low levels, and an upper-level anticyclonic circulation, consistent with a linear response to surface heating. The prevalence of the linear response could be because of a lack of background atmospheric variability in JJA but also because of the general weakness of eddies, which may play a significant role in modifying the linear response (Peng and Whitaker 1999; Kushnir et al. 2002).

Despite the apparent linear resemblance of the typical summertime response, the low-level cyclone is often seen to be over the SST anomaly itself and not displaced downstream, as in Hoskins and Karoly (1981) and the recent reanalysis work for summer of Ghosh et al. (2017). Analysis of the temperature advection equation also confirms the lack of role for cold-air advection implied by this lack of downstream displacement. This is consistent with the apparent dominance of the vertical advection term in the atmospheric response to the Gulf
Stream (Minobe et al. 2010) and also the response of the atmosphere to Gulf Stream variability (Wills et al. 2016) and variability over the Oyashio Extension region (Smirnov et al. 2015). Further work looking at the impact of horizontal resolution on these responses is required, however, to understand our results more fully. Our study has additional limitations (albeit deliberately chosen ones) in terms of the realism of both the magnitude and shape of the SST anomalies, and further work is required to better understand how our results relate to more realistic SST anomaly distributions and magnitudes.

Two midlatitude Pacific anomaly cases (i.e., P4C and $\mathrm{P} 4 \mathrm{E})$ produce robust projections onto the summer NAO, suggesting that there may be a source of predictability for the summer NAO from the midlatitude Pacific, but this is a very preliminary result. By contrast with these two cases, the remainder of our robust midlatitude SST responses were local and baroclinic, suggesting that any predictability from these anomalies will be quite local. This influence of SST anomalies on their immediate locality is generally consistent with Dong et al. (2013), who show, via regression models applied to reanalysis, that there are significant local correlations between the summer NAO index and the SSTs in the midlatitude Atlantic in both spring- and summertime.

One significant difference between our simulations and most others is the small spatial scales used for our SST anomalies, meaning that our anomalies may not as efficiently produce the larger-scale patterns found in, for example, Dong et al. (2013). An investigation of the type presented here, but with larger-scale patterns of SST anomalies, may therefore prove more fruitful for finding responses that project significantly onto the summer NAO and other large-scale patterns of variability. Our SST anomalies are also present throughout the annual cycle, so it may be that our JJA responses include the effect of the SST anomaly in spring on the summer circulation. While the large amplitude of our anomalies makes this unlikely, further investigation into seasonally varying SST anomalies is planned as future work. We are also yet to test anomalous heating over the Caribbean region, which could prove to be important for European summer predictability, as suggested in Hodson et al. (2010), Ossó et al. (2017), and Wulff et al. (2017). Conducting such experiments is an additional topic for future work.

\section{Comparison of winter and summer and conclusions of Part I and Part II}

\section{a. Response to tropical anomalies}

There is a large degree of similarity between DJF and JJA in the local responses to tropical anomalies, 
particularly in the Pacific. For example, the responses in case P1E can be compared in Fig. 4 for JJA and Fig. 4 of Part I for DJF. The character of the responses close to the SST anomalies are broadly similar across the seasons, suggesting that the same Matsuno-Gill-type responses are similarly at work in DJF as in JJA and that the impacts of different seasonal background wind changes are small. The main difference in these two responses is their magnitude, which is much larger in JJA. This implies a dependence of the response on the background state of the tropical atmosphere across the seasons even though some of these background-state differences are rather small. There is, however, a significant difference between the responses to tropical Atlantic SST anomalies between DJF and JJA that is robust across configurations. This seasonal contrast in the tropical Atlantic responses requires further investigation.

In terms of the remote responses to tropical SSTs, there are clearly more robust teleconnections between the tropical Pacific and the midlatitudes in DJF than in JJA. In terms of the large-scale Rossby wave picture, this is explained by the generally westward winds throughout the depth of the tropics in JJA, as is well known. However, the suggestion of our section 7 is that the teleconnections in JJA are still possible but are state dependent. Further experiments are required to investigate this possibility.

\section{b. Response to midlatitude anomalies}

In terms of the responses to midlatitude SST anomalies, only cases $\mathrm{P} 3 \mathrm{~W}-\mathrm{P} 3 \mathrm{E}$ and $\mathrm{P} 4 \mathrm{~W}$ produce robust responses in both winter and summer. These responses are very different, however, being a projection onto the model's internal modes of variability in winter and being a local baroclinic response in summer. There are clearly several major differences in the climatological circulation that could cause such a contrast between seasons. The EOF patterns, for example, are different between summer and winter, which would be significant if the ideas of Peng et al. (2003) are correct, who suggested that the strength of a response's projection onto the internal modes would be determined by their proximity to the EOF maxima/minima in, for example, geopotential height. It could be argued, however, that the model's EOF patterns are more similar across summer and winter than the stationary wave patterns, which are opposite in sign and have different maxima locations in winter and summer. We therefore propose the differences in stationary waves to be the most significant winter/summer contrast for the purpose of SST anomaly responses. In addition, the dominance of the vertical advection terms at $30^{\circ} \mathrm{N}$ in JJA leads to larger horizontal divergences aloft in JJA compared with DJF (not shown), meaning that a significant difference in responses between DJF and JJA is to be expected in these regions.

One other possible explanation for the seasonal contrast in responses in the same latitude locations is that a local baroclinic response is in fact present in winter at, for example, $30^{\circ} \mathrm{N}$ but is hidden by the larger response that projects onto the EOF. Such a scenario was shown by Deser et al. (2004), who investigated the atmospheric response to changes in polar SSTs and sea ice. They found that their atmospheric responses projected significantly onto the internal modes of the system but developed a method to subtract off the internal mode portion of the response, which revealed a classic baroclinic response. We have implemented this method for our winter results but could not see a baroclinic response as clearly as in Deser et al. (2004). Despite this, the baroclinic response being hidden by the larger internal mode component of the response in DJF remains a likely scenario. This would therefore suggest that differences in the internal modes, stationary waves, and background eddy activity may well play a significant role in creating contrasting responses between DJF and JJA. This will be investigated as part of our future work.

\section{c. Summary}

To give a general summary of our findings from this paper and Part I, focusing only on those results that we believe to be robust, our conclusions are as follows:

1) In winter (DJF), tropical SST anomalies produce a robust local response and, possibly through the action of propagating Rossby waves, can in some circumstances produce a robust midlatitude response.

2) In summer (JJA), similar tropical Pacific SST anomalies produce a similarly robust local response to that in winter. However, the signal finds it hard to propagate into midlatitudes under climatological conditions because the predominantly westward winds prevent Rossby wave propagation out of the tropics. There are time periods, however, when Rossby waves can propagate out of the tropics and could provide a tropical-midlatitude teleconnection as in winter.

3) In the midlatitudes, in both summer and winter, SST anomalies do not typically produce as strong a response in the free atmosphere as do tropical anomalies. The signal-to-noise ratio is worse and the background conditions are much less constrained than in the tropics because of baroclinic activity.

4) In winter, midlatitude SST anomalies can nevertheless produce a robust remote response, particularly if the response projects onto internal modes of variability. 
5) In summer, midlatitude SST anomalies produce local baroclinic responses and only occasionally produce a robust remote response.

6) Cold-air advection does not seem to be important in any of the midlatitude responses in JJA and is only important in some cases in DJF. The vertical term in the temperature advection equation seems much more important in all cases.

Discussion of the caveats and exceptions to these results can be found in the main text, as can their explanations. Topics for future work include studying the reasons for the different types of responses seen in midlatitudes in winter and summer, with the occasional large-scale responses in winter contrasting with the generally local and linear responses in summer. Possible causes include the seasonal changes in stationary wave patterns, seasonal changes in eddy fluxes and in modes of internal variability, and changes in the dominant terms in the temperature advection equation.

Our conclusions above suggest that seasonal predictability due to long-lived SST anomalies may come primarily from the tropics in winter, secondarily from the midlatitudes in winter and the tropics in summer, and rarely from midlatitudes in summer. Experiments with higher-resolution models, as well as further comparison with observations, may indicate more predictability in midlatitudes if the SST signal can be better felt in the free atmosphere.

Acknowledgments. We thank many people for helpful discussions, including Mat Collins, Issac Held, Christopher O'Reilly, and Tim Woollings. We also thank Martin Jucker for his help with MiMA and James Penn, Ruth Geen, and Penelope Maher for their continued collaboration on the Isca system. SIT is supported by the Natural Environment Research Council (Grant NE/M006123/1) and GKV also acknowledges support from the Royal Society (Wolfson Foundation), the Leverhulme Trust, and the Newton Fund-CSSP. The code required to run the Isca model framework, including the setup used in the present work, is provided on GitHub (at www.github.com/ExeClim/ Isca). Information on running the model is also provided online (at www.exeter.ac.uk/isca).

\section{REFERENCES}

Bony, S., K. M. Lau, and Y. C. Sud, 1997: Sea surface temperature and large-scale circulation influences on tropical greenhouse effect and cloud radiative forcing. J. Climate, 10, 2055-2077, https:// doi.org/10.1175/1520-0442(1997)010<2055:SSTALS>2.0.CO;2.

Charney, J. G., and P. G. Drazin, 1961: Propagation of planetary-scale disturbances from the lower into the upper atmosphere. J. Geophys. Res., 66, 83-109, https://doi.org/ 10.1029/JZ066i001p00083.
Dee, D. P., and Coauthors, 2011: The ERA-Interim reanalysis: Configuration and performance of the data assimilation system. Quart. J. Roy. Meteor. Soc., 137, 553-597, https://doi.org/10.1002/qj.828.

Deser, C., G. Magnusdottir, R. Saravanan, and A. Phillips, 2004: The effects of North Atlantic SST and sea ice anomalies on the winter circulation in CCM3. Part II: Direct and indirect components of the response. J. Climate, 17, 877-889, https://doi.org/ 10.1175/1520-0442(2004)017<0877:TEONAS > 2.0.CO;2.

Dong, B., R. T. Sutton, T. Woollings, and K. Hodges, 2013: Variability of the North Atlantic summer storm track: Mechanisms and impacts on European climate. Environ. Res. Lett., 8, 034037, https://doi.org/10.1088/1748-9326/8/3/034037.

Folland, C. K., J. Knight, H. W. Linderholm, D. Fereday, S. Ineson, and J. W. Hurrel, 2009: The summer North Atlantic oscillation: Past, present, and future. J. Climate, 22, 1082-1103, https://doi.org/10.1175/2008JCLI2459.1.

Frankignoul, C., 1985: Sea surface temperature anomalies, planetary waves, and air-sea feedback in the middle latitudes. Rev. Geophys., 23, 357-390, https://doi.org/10.1029/RG023i004p00357.

Gastineau, G., and C. Frankignoul, 2015: Influence of the North Atlantic SST variability on the atmospheric circulation during the twentieth century. J. Climate, 28, 1396-1416, https://doi. org/10.1175/JCLI-D-14-00424.1.

Ghosh, R., W. A. Müller, J. Baehr, and J. Bader, 2017: Impact of observed North Atlantic multidecadal variations to European summer climate: A linear baroclinic response to surface heating. Climate Dyn., 48, 3547-3563, https://doi.org/10.1007/ s00382-016-3283-4.

Gill, A. E., 1980: Some simple solutions for heat-induced tropical circulation. Quart. J. Roy. Meteor. Soc., 106, 447-462, https:// doi.org/10.1002/qj.49710644905.

Hodson, D. L., R. T. Sutton, C. Cassou, N. Keenlyside, Y. Okumura, and T. Zhou, 2010: Climate impacts of recent multidecadal changes in Atlantic Ocean sea surface temperature: A multimodel comparison. Climate Dyn., 34, 1041-1058, https://doi.org/ 10.1007/s00382-009-0571-2.

Hoskins, B. J., and D. J. Karoly, 1981: The steady linear response of a spherical atmosphere to thermal and orographic forcing. J. Atmos. Sci., 38, 1179-1196, https://doi.org/10.1175/ 1520-0469(1981)038<1179:TSLROA > 2.0.CO;2.

Hurwitz, M. M., P. A. Newman, and C. I. Garfinkel, 2012: On the influence of North Pacific sea surface temperature on the Arctic winter climate. J. Geophys. Res., 117, D19110, https:// doi.org/10.1029/2012JD017819.

Kobayashi, S., and Coauthors, 2015: The JRA-55 Reanalysis: General specifications and basic characteristics. J. Meteor. Soc. Japan, 93, 5-48, https://doi.org/10.2151/jmsj.2015-001.

Kushnir, Y., W. A. Robinson, I. Bladé, N. M. J. Hall, S. Peng, and R. Sutton, 2002: Atmospheric GCM response to extratropical SST anomalies: Synthesis and evaluation. J. Climate, 15, 2233-2256, https://doi.org/10.1175/1520-0442(2002)015<2233: AGRTES $>2.0 . \mathrm{CO} ; 2$.

Lee, S. K., C. Wang, and B. E. Mapes, 2009: A simple atmospheric model of the local and teleconnection responses to tropical heating anomalies. J. Climate, 22, 272-284, https://doi.org/ 10.1175/2008JCLI2303.1.

Matsuno, T., 1966: Quasi-geostrophic motions in the equatorial area. J. Meteor. Soc. Japan, 44, 25-43, https://doi.org/10.2151/ jmsj1965.44.1_25.

McKinnon, K. A., A. Rhines, M. P. Tingley, and P. Huybers, 2016: Long-lead predictions of eastern United States hot days from Pacific sea surface temperatures. Nat. Geosci., 9, 389-394, https://doi.org/10.1038/ngeo2687. 
Minobe, S., A. Kuwano-Yoshida, N. Komori, S.-P. Xie, and R. J. Small, 2008: Influence of the Gulf Stream on the troposphere. Nature, 452, 206-209, https://doi.org/10.1038/nature06690.

, M. Miyashita, A. Kuwano-Yoshida, H. Tokinaga, and S. P. Xie, 2010: Atmospheric response to the Gulf Stream: Seasonal variations. J. Climate, 23, 3699-3719, https://doi.org/10.1175/2010JCLI3359.1.

Ossó, A., R. Sutton, L. Shaffrey, and B. Dong, 2017: Observational evidence of European summer weather patterns predictable from spring. Proc. Natl. Acad. Sci. USA, 115, 59-63, https://doi.org/10.1073/pnas.1713146114.

Peng, S., and J. S. Whitaker, 1999: Mechanisms determining the atmospheric response to midlatitude SST anomalies. J. Climate, 12, 1393-1408, https://doi.org/10.1175/1520-0442(1999)012<1393: MDTART $>2.0 . \mathrm{CO} ; 2$.

spheric internal variability and the responses to an extratropical SST anomaly. J. Climate, 14, 2943-2959, https://doi.org/ 10.1175/1520-0442(2001)014<2943:RBAIVA > 2.0.CO;2.

_,$\ldots$, and S. Li, 2003: Mechanisms for the NAO responses to the North Atlantic SST tripole. J. Climate, 16, 19872004, https://doi.org/10.1175/1520-0442(2003)016<1987: MFTNRT $>2.0 . \mathrm{CO} ; 2$.

Rayner, N. A., D. Parker, E. Horton, C. Folland, L. Alexander, D. Rowell, E. Kent, and A. Kaplan, 2003: Global analyses of sea surface temperature, sea ice, and night marine air temperature since the late nineteenth century. J. Geophys. Res., 108, 4407, https://doi.org/10.1029/2002JD002670.

Saeed, S., N. Van Lipzig, W. A. Müller, F. Saeed, and D. Zanchettin, 2014: Influence of the circumglobal wavetrain on European summer precipitation. Climate Dyn., 43, 503-515, https://doi.org/10.1007/s00382-013-1871-0.

Scaife, A. A., and Coauthors, 2017: Tropical rainfall, Rossby waves and regional winter climate predictions. Quart. J. Roy. Meteor. Soc., 143, 1-11, https://doi.org/10.1002/qj.2910.
Smirnov, D., M. Newman, M. A. Alexander, Y. O. Kwon, and C. Frankignoul, 2015: Investigating the local atmospheric response to a realistic shift in the Oyashio sea surface temperature front. J. Climate, 28, 1126-1147, https://doi.org/10.1175/ JCLI-D-14-00285.1.

Sutton, R. T., and D. L. R. Hodson, 2005: Atlantic Ocean forcing of North American and European summer climate. Science, 309, 115-118, https://doi.org/10.1126/science.1109496.

— cooling of the North Atlantic Ocean. J. Climate, 20, 891-907, https://doi.org/10.1175/JCLI4038.1.

Taylor, K. E., D. Williamson, and F. Zwiers, 2000: The sea surface temperature and sea-ice concentration boundary conditions for AMIP II simulations. PCMDI Rep. 60, 25 pp.

Thomson, S. I., and G. K. Vallis, 2018: Atmospheric response to SST anomalies. Part I: Background-state dependence, teleconnections, and local effects in winter. J. Atmos. Sci., 75, 4107-4124, 10.1175/JAS-D-17-0297.1.

Vallis, G. K., 2017: Atmospheric and Oceanic Fluid Dynamics. 2nd ed. Cambridge University Press, 964 pp., https://doi.org/ $10.1017 / 9781107588417$.

_ - and Coauthors, 2018: Isca, v1.0: A framework for the global modelling of the atmospheres of Earth and other planets at varying levels of complexity. Geosci. Model Dev., 11, 843-859, https://doi.org/10.5194/gmd-11-843-2018.

Wills, S. M., D. W. J. Thompson, and L. M. Ciasto, 2016: On the observed relationships between variability in Gulf Stream sea surface temperatures and the atmospheric circulation over the North Atlantic. J. Climate, 29, 3719-3730, https://doi.org/ 10.1175/JCLI-D-15-0820.1.

Wulff, C. O., R. J. Greatbatch, D. I. Domeisen, G. Gollan, and F. Hansen, 2017: Tropical forcing of the summer East Atlantic pattern. Geophys. Res. Lett., 44, 11 166-11173, https://doi.org/ 10.1002/2017GL075493. 